\title{
High-purity Seed Production of Doubled Haploid Chinese Cabbage [Brassica rapa L. ssp. pekinensis (Lour.)] Through Microspore Culture
}

\author{
Mi-Hyun Lee*, Chan Ju Lim, In-Ho Lee, Jun-Ho Song \\ R\&D center, Asiaseed Co. Ltd., Iwhangri, 447-2, Icheonsi, Gyeonggido, Korea
}

\begin{abstract}
The purpose of this study was to produce doubled haploid red color heading type Chinese cabbage using isolated microspore culture. Genotypic differences in embryogenic response and regenerative ability of microspore-derived embryos to plants were observed. A high rate of plant regeneration from microspore-derived embryos was achieved by an improved protocol involving replacement of culture media and adjustment of heat shock temperature. More than $60 \%$ of regenerated plants were spontaneous doubled haploids. Haploids were characterized by short and malformed stamen and few viable pollen grains as compared to spontaneous doubled haploids and dihaploids. The seeds harvested from the 142 spontaneous doubled haploid plants were designated as $\mathrm{H} 1 ; 25$ seeds in each population was grown and characterized. The $\mathrm{H} 1$ generation has been shown to display considerable phenotypic variation and high purity. These spontaneous doubled haploids may be directly exploited as new varieties in a red colored Chinese cabbage breeding program.
\end{abstract}

Keywords Double haploid, Microspore culture, Plant regeneration, Red color heading type Chinese cabbage, Seed

\section{INTRODUCTION}

Red color heading type Chinese cabbage [Brassica rapa L. ssp. pekinensis (Lour.)] is an important crop receiving greater attention by seed companies due to the increased market demand. Most of the commercial cultivars of Chinese cabbage are $F_{1}$ hybrids, which require a sufficient degree of homozygous parental lines. Conventional breeding in Chinese cabbage is time-consuming and labor-intensive. Haploid breeding is more efficient than conventional plant breeding for the generation of diploid homozygous lines. Generally, to obtain a pure homozygous line from a hybrid, it needs at least six or seven generations by self fertilization, while it only needs a single or several generations by haploid breeding.

Microspore culture potentially offers a very effective means of producing homozygous lines of Brassica plants. Since the successful isolation of microspore culture of Brassica napus was reported (Lichter 1982), microspore culture has been reported in other Brassica species (Sato et al. 1989; Baillie et al. 1992; Cao et al. 1994; Wong et al. 1996; Wang et al. 2009). However, microspore culture was not very successful in B. rapa (Guo and Pulli 1996), compared with B. napus (Zhou et al. 2002; Gu et al. 2004; Leroux et al. 2009). Just as there are differences in embryogenic response among species, there are also genotypic differences in microspore culture response. Thus, the routine protocols of microspore culture of Brassica cannot be simply used for a broad spectrum of breeding materials and should be clarified many factors such culture media and culture conditions for novel materials.

Nowadays doubled haploidy is being featured in cultivar production of many crops. According to Thomas et al. (2003), there are currently around 300 doubled haploid derived cutivars in 12 species, but this is likely to be a gross underestimate, as information from some countries is scant and many breeders are reluctant to reveal their production

Received April 22, 2014; Revised June 18, 2014; Accepted June 18, 2014; Published June 30, 2014

*Comesponding author Mi-Hyun Lee, biotech@asiaseed.co.kr, Tel: +81-70-4016-8477, Fax: +81-31-622-9887 
methods. Doubled haploidy has been extremely effective in cultivar production in barley, rice and rapeseed. The barley cultivar "Mingo" was the first major double haploid crop cultivar and produced and grown in Canada in the late 1970's (Ho and Jones 1980). The blackleg resistance rapeseed doubled haploid cultivar "Quantum" captured $30 \%$ of the acreage in Canada in 1995 (Stringham et al. 1995).

Aiming to improve the embryoid induction rate and produce haploid plants for Brassica breeding, in this paper, we study the effects of genotypes, temperature preculture, and culture medium, on the microspore embryo formation.

\section{MATERIALS AND METHODS}

\section{Plant material and growth conditions}

A set containing five genotypes of Brassica rapa L. ssp. pekinensis (Lour.) (AS20, 21, 23, 24, 34) was tested as donor plants. The donor plants were grown in a growth chamber at $23 / 20^{\circ} \mathrm{C}$ (day/night) with a $16 / 8 \mathrm{~h} \mathrm{light/dark}$ photoperiod until they had eight leaves. Vernalization of donor plants was conducted with a combination of $8^{\circ} \mathrm{C}$ and $8 \mathrm{~h}$ photoperiod for eight weeks. They were then grown to flowering in a growth chamber at $23 / 20^{\circ} \mathrm{C}$ (day/night) with a 16/8 h light/dark.

\section{Isolation of microspores}

The microspore isolation procedure was based on the study by Sato et al. (1989) with some modifications. Unopened young flower buds 2.0 to $3.0 \mathrm{~mm}$ in length were sterilized in sodium hypochlorite solution containing $2 \%$ for $10 \mathrm{~min}$. The buds were washed three times with sterilized distilled water for $5 \mathrm{~min}$, and then gently macerated in a washing solution B5 medium (Gambory et al. 1968) supplemented with $13 \%$ sucrose for 5 min using mortar and pestle. The macerated buds were passed through sieves (45

$\mathrm{m})$, the filtrates were centrifuged three times at $1000 \mathrm{rpm}$ for $3 \mathrm{~min}$ and the supernatants were discarded. The pellets were resuspended in culture medium. The harvested microspores adjusted to a density of $2 \times 10^{5} / \mathrm{ml}$ in culture medium were plated in $60 \times 15 \mathrm{~mm}$ plastic petri-dishes containing $2.5 \mathrm{ml}$ liquid medium. An addition of a $0.1 \mathrm{ml}$ drop of $1 \%$ activated charcoal to the culture dishes was plated. The dishes were sealed with parafilm.

\section{Pretreatments and culture of microspores}

In the heat shock experiment, isolated microspores were incubated under dark conditions at 30 and $32.5^{\circ} \mathrm{C}$ for 1,2 and 3 days (Table 1), and then maintained at $25^{\circ} \mathrm{C}$ under dark conditions for 17 days. To test the effect of culture medium on embryogenesis, the NLM medium and halfstrength NLM medium supplemented with different

Table 1. Treatments of the heat shock and culture medium of red colored Chinese cabbage in this study.

\begin{tabular}{cccc}
\hline \hline \multirow{2}{*}{ B. N. } & Culture medium & \multicolumn{2}{c}{ Temperature condition } \\
\cline { 3 - 4 } & $1,2,3,4$ & Temperature $\left({ }^{\circ} \mathrm{C}\right)$ & Time $(\mathrm{d})$ \\
\hline AS20 & $1,2,3,4$ & $30,32.5$ & $1 \mathrm{~d}, 2 \mathrm{~d}, 3 \mathrm{~d}$ \\
AS21 & 1,2 & $30,32.5$ & $1 \mathrm{~d}, 2 \mathrm{~d}, 3 \mathrm{~d}$ \\
AS23 & $1,2,3,4$ & $30,32.5$ & $1 \mathrm{~d}, 2 \mathrm{~d}, 3 \mathrm{~d}$ \\
AS24 & $1,2,3,4$ & $30,32.5$ & $1 \mathrm{~d}, 2 \mathrm{~d}, 3 \mathrm{~d}$ \\
AS34 & & $30,32.5$ & $1 \mathrm{~d}, 2 \mathrm{~d}, 3 \mathrm{~d}$ \\
\hline
\end{tabular}

Table 2. Culture medium for microspore culture of red colored Chinese cabbage in this study.

\begin{tabular}{cc}
\hline \hline No. & Culture medium \\
\hline 1 & $\mathrm{NLN}+\mathrm{S}_{13} \%+\mathrm{CaNO}_{3} 0.5 \mathrm{~g} / \mathrm{L}+\mathrm{NAA} 0.5 \mathrm{mg} / \mathrm{L}+\mathrm{BAP} 0.5 \mathrm{mg} / \mathrm{L}$ \\
2 & $\mathrm{NLN}+\mathrm{S} 13 \%+\mathrm{CaNO}_{3} 0.5 \mathrm{~g} / \mathrm{L}+\mathrm{NAA} 1.0 \mathrm{mg} / \mathrm{L}+\mathrm{BAP} 1.0 \mathrm{mg} / \mathrm{L}$ \\
3 & $\mathrm{NLN}+\mathrm{S} 15 \%+\mathrm{CaNO}_{3} 0.5 \mathrm{~g} / \mathrm{L}+\mathrm{NAA} 1.0 \mathrm{mg} / \mathrm{L}+\mathrm{BAP} 1.0 \mathrm{mg} / \mathrm{L}$ \\
4 & $1 / 2 \mathrm{NLN}+\mathrm{S} 13 \%+\mathrm{CaNO}_{3} 0.25 \mathrm{~g} / \mathrm{L}+\mathrm{NAA} 0.5 \mathrm{mg} / \mathrm{L}+\mathrm{BAP} 0.5 \mathrm{mg} / \mathrm{L}$ \\
\hline
\end{tabular}


concentration of growth regulators were tested for their efficient embryogenesis (Table 2). Various concentrations $(0.5$ and $1.0 \mathrm{mg} / \mathrm{L})$ of 6-benzylaminopurine (BAP) and naphthalene acetic acid (NAA) were tested. Each treatment was carried out with three independent replications (three cultures).

\section{Plant regeneration and soil transformation}

After 17 days of microspore culture, the dishes were transferred to a slow rotary shaker ( $80 \mathrm{rpm})$ under a photoperiod of $16 \mathrm{~h}$ at $23^{\circ} \mathrm{C}$ until the embryos became green. At the cotyledon stage, embryos were transferred to dishes containing solid MS (Murashige and Skoog 1962) medium. Approximately three weeks later when shoots developed from the embryos, they were transferred onto solid 1/2MS medium for rooting. The conversion percentages of microspore embryos to plantlets were calculated. After four weeks, rooted plantlets were vernalized at $8^{\circ} \mathrm{C}$ for at least two months. Thereafter they were transferred to a soil-perlite mixture in a pot and were kept for two more weeks at $23^{\circ} \mathrm{C}$, with low light intensity, and high humidity. This was followed by gradual adaptation to glasshouse conditions.

\section{Determination of doubled haploid}

The proportion of spontaneous doubled haploid was calculated by dividing the number of fertilized plants by the total number of plants observed.

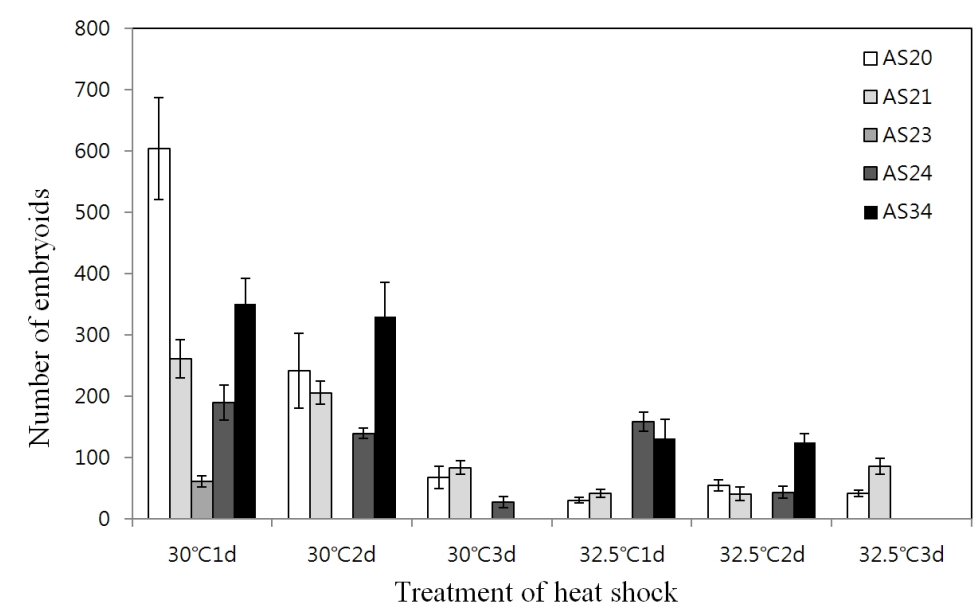

Fig. 1. Effect of heat shock temperature and duration on microspore embryogenesis in five genotypes.

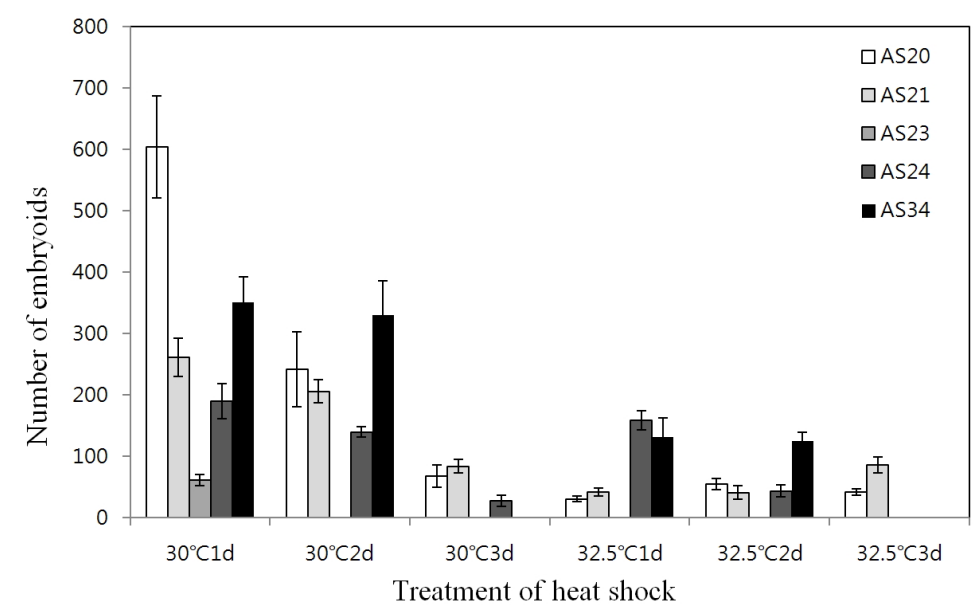

Fig. 2. Effect of growth medium on microspore embryogenesis in five genotypes. Four different media $(1,2,3,4)$ were used for microspore culture (Table 2). 


\section{Doubled haploid (DH) line generation}

Flower morphology and fertility of plants were investigated. Doubled haploid plants were grown and allowed to self-pollination to produce the corresponding seed (H1). For investigation of homozygous purity of $\mathrm{H} 1$, seeds were sown in the experimental field.

\section{RESULTS}

\section{Effect of temperature and duration of heat shock}

In the current study, five $\mathrm{F}_{1}$ hybrids of Red color heading type Chinese cabbage were evaluated for their capacity to produce microspore-derived embryos on various conditions. Five genotypes were successfully induced to produce embryoids. Evident differences in microspore embryogenesis were observed among the five tested donor plants (Table 3). The effect of different temperature and duration of heat shock prior to culture at the normal temperature $\left(25^{\circ} \mathrm{C}\right)$ on the embryoid induction was investigated. For whole genotypes, the optimum heat shock treatment observed was at $30^{\circ} \mathrm{C}$ for one day which resulted in $62 \sim 604$ embryoids; however, longer duration decreased the number of embryoids (Fig. 1).

\section{Effect of culture medium on microspore embryogenesis}

The effect of the concentration of NLM medium on isolated microspore culture was studied. The results were presented in Fig. 2. It showed that the embryoid induction was significantly increased with full-strength NLM medium. The combination of $0.5 \mathrm{mg} / \mathrm{L}$ BAP and NAA was very promising; the embryo induction was increased up to two-fold on full-strength NLM, which is significantly higher than $1.0 \mathrm{mg} / \mathrm{L} \mathrm{BAP}$ and NAA. It can be seen that concentration of NLM as well as growth regulators play an important role on the embryoid induction in isolated microspore culture of red colored Chinese cabbage.

Table 3. Effects of heat shock and the combinations of culture medium on embryoids induction.

\begin{tabular}{|c|c|c|c|c|c|c|c|}
\hline \multirow[b]{2}{*}{ B.N } & \multirow[b]{2}{*}{ Culture media } & \multicolumn{6}{|c|}{ Heat treatment } \\
\hline & & $30^{\circ} \mathrm{C}$ & $30^{\circ} \mathrm{C}$ & $30^{\circ} \mathrm{C}$ & $32.5^{\circ} \mathrm{C}$ & $32.5^{\circ} \mathrm{C}$ & $32.5^{\circ} \mathrm{C}$ \\
\hline \multirow{4}{*}{ AS20 } & 1 & $427 \pm 98$ & $184 \pm 100$ & $42 \pm 25$ & $0 \pm 0$ & $0 \pm 0$ & $19 \pm 5$ \\
\hline & 2 & $171 \pm 59$ & $56 \pm 20$ & $26 \pm 12$ & $0 \pm 0$ & $0 \pm 0$ & $23 \pm 5$ \\
\hline & 3 & $6 \pm 2$ & $2 \pm 1$ & $0 \pm 0$ & $0 \pm 0$ & $0 \pm 0$ & $0 \pm 0$ \\
\hline & 4 & $0 \pm 0$ & $0 \pm 0$ & $0 \pm 0$ & $31 \pm 9$ & $55 \pm 19$ & $0 \pm 0$ \\
\hline \multirow{4}{*}{ AS21 } & 1 & $253 \pm 58$ & $175 \pm 23$ & $59 \pm 13$ & $0 \pm 0$ & $0 \pm 0$ & $45 \pm 17$ \\
\hline & 2 & $2 \pm 1$ & $0 \pm 0$ & $25 \pm 9$ & $0 \pm 0$ & $0 \pm 0$ & $41 \pm 9$ \\
\hline & 3 & $7 \pm 3$ & $31 \pm 15$ & $0 \pm 0$ & $0 \pm 0$ & $0 \pm 0$ & $0 \pm 0$ \\
\hline & 4 & $0 \pm 0$ & $0 \pm 0$ & $0 \pm 0$ & $42 \pm 12$ & $41 \pm 22$ & $0 \pm 0$ \\
\hline \multirow{2}{*}{ AS23 } & 1 & $39 \pm 8$ & $0 \pm 0$ & $0 \pm 0$ & $0 \pm 0$ & $0 \pm 0$ & $0 \pm 0$ \\
\hline & 2 & $23 \pm 10$ & $0 \pm 0$ & $0 \pm 0$ & $0 \pm 0$ & $0 \pm 0$ & $0 \pm 0$ \\
\hline \multirow{4}{*}{ AS24 } & 1 & $166 \pm 42$ & $96 \pm 11$ & $0 \pm 0$ & $0 \pm 0$ & $0 \pm 0$ & $0 \pm 0$ \\
\hline & 2 & $19 \pm 13$ & $7 \pm 4$ & $0 \pm 0$ & $0 \pm 0$ & $0 \pm 0$ & $0 \pm 0$ \\
\hline & 3 & $2 \pm 1$ & $37 \pm 2$ & $0 \pm 0$ & $120 \pm 22$ & $21 \pm 9$ & $0 \pm 0$ \\
\hline & 4 & $3 \pm 1$ & 0 & $28 \pm 19$ & $39 \pm 8$ & $23 \pm 11$ & $0 \pm 0$ \\
\hline \multirow{4}{*}{ AS34 } & 1 & $241 \pm 33$ & $245 \pm 67$ & $0 \pm 0$ & $0 \pm 0$ & $0 \pm 0$ & $0 \pm 0$ \\
\hline & 2 & $72 \pm 42$ & $0 \pm 0$ & $0 \pm 0$ & $0 \pm 0$ & $0 \pm 0$ & $0 \pm 0$ \\
\hline & 3 & $38 \pm 9$ & $85 \pm 45$ & $0 \pm 0$ & $120 \pm 55$ & $125 \pm 29$ & $0 \pm 0$ \\
\hline & 4 & $0 \pm 0$ & $0 \pm 0$ & $0 \pm 0$ & $12 \pm 7$ & $0 \pm 0$ & $0 \pm 0$ \\
\hline
\end{tabular}




\section{Plant regeneration and acclimatization}

The embryos at the cotyledonary stage (21 days old) were planted onto hormone-free solid MS medium for germination and further development (Fig. 3A). After three weeks, some embryos rapidly developed into plants. These germinated embryos were transferred to plastic or glass vessels containing solid 1/2MS for rooting (Fig. 3B-C). The embryos that developed abnormally showed swollen hypocotyls and cotyledons. The percentage of plant regeneration varied from $16.2 \%(\mathrm{AS} 21)$ to $3.2 \%(\mathrm{AS} 23)$, as shown in Table 4 . The plantlets were transferred to a cold frame to vernalize for eight weeks (Fig. 3C). After vernalization in culture bottle, plantlets were transferred to soil in a greenhouse (Fig. 3D). The percentage of planting of plantlets was $80.3 \%$ (AS24) to $0 \%$ (AS23) (Table 4). The proportion of spontaneous doubled haploid was calculated by dividing the number of doubled haploid plants by the total number of plants observed. Different spontaneous doubling frequencies were observed for different genotypes (Table 4). However, difference of the fertility rate was not detected depending on medium. The maximum spontaneous doubling frequency was observed in $\operatorname{AS} 24$ (64.2\%), followed by AS34 (45\%).

\section{Seed purity of doubled haploid population}

After about two months, the regenerated plants blossomed. The differences between plants of haploid and doubled haploid were analyzed at the morphological level. Doubled

Table 4. Differences of embryoids and fertile plant production through isolated microspore culture of Red Chinese cabbage.

\begin{tabular}{|c|c|c|c|c|c|c|c|c|}
\hline \multirow[b]{2}{*}{ B.N } & \multirow{2}{*}{$\begin{array}{l}\text { No. of } \\
\text { culture media }\end{array}$} & \multirow{2}{*}{$\begin{array}{l}\text { Number of } \\
\text { embryoid (A) }\end{array}$} & \multicolumn{2}{|c|}{ Plantlets } & \multicolumn{2}{|c|}{ Planting } & \multicolumn{2}{|c|}{ Fertility } \\
\hline & & & $\begin{array}{l}\text { Number } \\
\text { (B) }\end{array}$ & $\begin{array}{l}\mathrm{B} / \mathrm{A} \\
(\%)\end{array}$ & $\begin{array}{l}\text { Number } \\
\text { (E) }\end{array}$ & $\begin{array}{l}\mathrm{E} / \mathrm{B} \\
(\%)\end{array}$ & $\begin{array}{l}\text { Number } \\
\text { (F) }\end{array}$ & $\begin{array}{l}\mathrm{F} / \mathrm{E} \\
(\%)\end{array}$ \\
\hline \multirow{5}{*}{ AS20 } & 1 & $672 \pm 228$ & 88 & 13.1 & 51 & 58.0 & 29 & 56.9 \\
\hline & 2 & $276 \pm 96$ & 36 & 13.0 & 17 & 47.2 & 9 & 52.9 \\
\hline & 3 & $8 \pm 3$ & 1 & 12.5 & 0 & 0 & 0 & 0 \\
\hline & 4 & $86 \pm 28$ & 11 & 12.8 & 4 & 36.4 & 2 & 50.0 \\
\hline & Total & $1042 \pm 355$ & 136 & 13.1 & 71 & 52.2 & 41 & 57.7 \\
\hline \multirow{5}{*}{ AS21 } & 1 & $532 \pm 111$ & 87 & 16.4 & 59 & 67.8 & 29 & 49.2 \\
\hline & 2 & $68 \pm 19$ & 8 & 11.8 & 4 & 50.0 & 2 & 50.0 \\
\hline & 3 & $38 \pm 18$ & 4 & 10.5 & 3 & 75.0 & 2 & 66.7 \\
\hline & 4 & $83 \pm 34$ & 18 & 21.7 & 11 & 61.1 & 7 & 63.6 \\
\hline & Total & $721 \pm 182$ & 117 & 16.2 & 77 & 65.8 & 40 & 51.9 \\
\hline \multirow{3}{*}{$\mathrm{AS} 23$} & 1 & $39 \pm 8$ & 2 & 5.1 & 0 & 0 & 0 & 0 \\
\hline & 2 & $23 \pm 10$ & 0 & 0.0 & 0 & 0 & 0 & 0 \\
\hline & Total & $62 \pm 18$ & 2 & 3.2 & 0 & 0 & 0 & 0 \\
\hline \multirow{5}{*}{$\mathrm{AS} 24$} & 1 & $262 \pm 53$ & 30 & 11.5 & 25 & 83.3 & 17 & 68.0 \\
\hline & 2 & $26 \pm 17$ & 2 & 7.7 & 2 & 100.0 & 1 & 50.0 \\
\hline & 3 & $180 \pm 34$ & 24 & 13.3 & 19 & 79.2 & 12 & 63.2 \\
\hline & 4 & $93 \pm 39$ & 10 & 10.8 & 7 & 70.0 & 4 & 57.1 \\
\hline & Total & $561 \pm 143$ & 66 & 11.8 & 53 & 80.3 & 34 & 64.2 \\
\hline \multirow{5}{*}{ AS34 } & 1 & $486 \pm 100$ & 51 & 10.5 & 38 & 74.5 & 16 & 42.1 \\
\hline & 2 & $72 \pm 42$ & 9 & 12.5 & 5 & 55.6 & 2 & 40.0 \\
\hline & 3 & $368 \pm 130$ & 28 & 7.6 & 17 & 60.7 & 9 & 52.9 \\
\hline & 4 & $12 \pm 7$ & 1 & 8.3 & 0 & 0 & 0 & 0 \\
\hline & Total & 938 & 89 & 9.5 & 60 & 67.4 & 27 & 45.0 \\
\hline
\end{tabular}



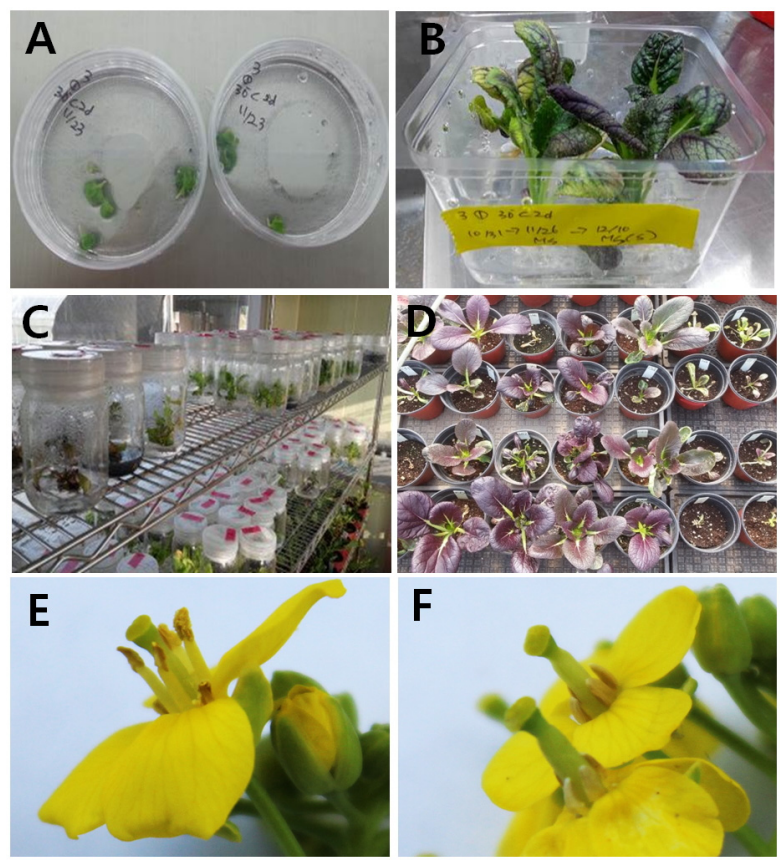

Fig. 3. Differentiation of haploid and spontaneous doubled haploid plants through isolated microspore culture of red colored Chinese cabbage. (A) Microspore-derived embryoids after three weeks of culture. (B) Plantlets from embryoids after four weeks. (C) Vernalization of plantlets $8^{\circ} \mathrm{C}$ for at least two months. (D) Acclimatization of vernalizated plantlets. (E-F) Flower of spontaneous (E) doubled haploid and (F) haploid plants.

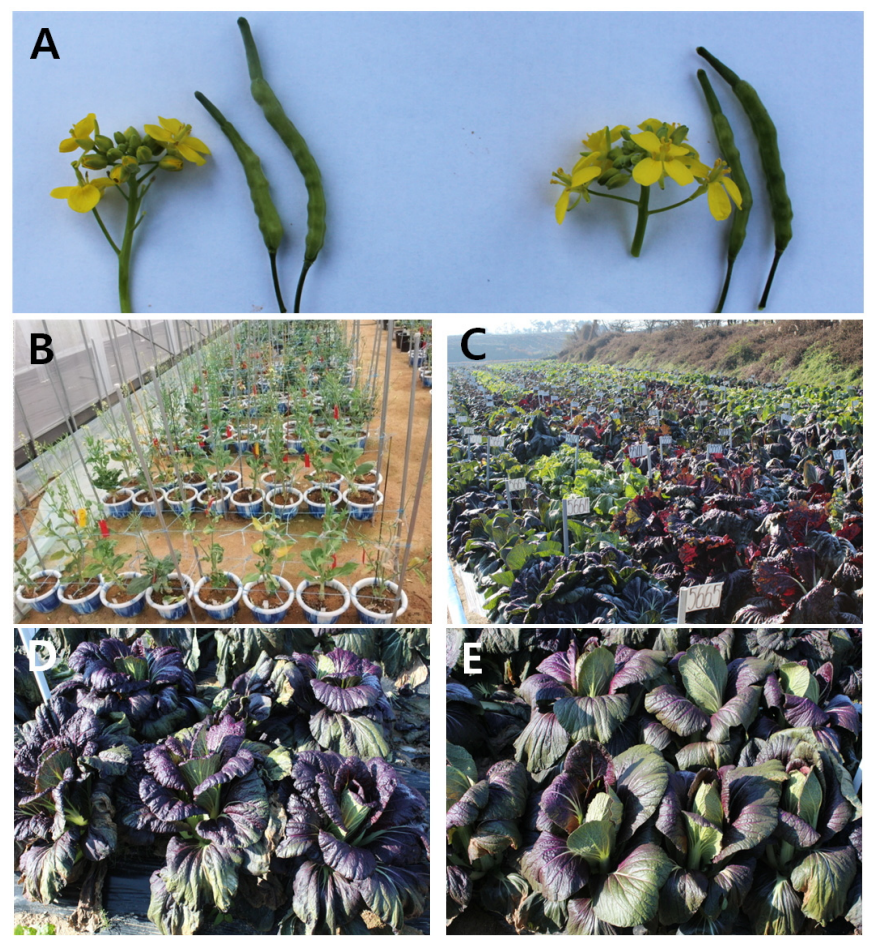

Fig. 4. Seed purity of doubled haploid population through isolated microspore culture of red colored Chinese cabbage. (A) Flowering shoots and silique of spontaneous doubled haploid (right) and diploid (left) of red colored Chinese cabbage. (B) Self-pollination of doubled haploid plants. (C) Field test of next generation (H1) of 142 spontaneous doubled haploid population. (D-E) H1 displayed variation for phenotype and uniformity in field. 
haploid plants were fertile with normal anthers and many viable pollen grains (Fig. 3E). Haploid plants were sterile with short and malformed stamen and few viable pollen grains (Fig. 3F). The diameter of a flower and the length of anthers in haploids decreased by 1.4 and 1.8 times compared to doubled haploids, respectively (data not shown). Differences of flower and silique morphology were not observed between doubled haploid and dihaploid plants. Silique has pure seeds after self-pollination (Fig. 4A). The seed harvested from doubled haploid plants was designated (H1). A total of 25 seeds (H1) from each doubled haploid population were sown to observe uniformity in the field. The $\mathrm{H} 1$ generations displayed a large genotypic variation and were considered fixed (Fig. 4 C-E).

\section{DISCUSSION}

Microspore culture of Brassica crops is an attractive system for production of haploid plantlets. However, an efficient protocol for genotype-independent haploid induction is still lacking and the use of doubled haploids is limited. Genotype of the donor plant is regarded as one of the important factors affecting microspore culture in Brassica crops (Guo and Pulli 2000; Dias and Correia 2002; Zhang et al. 2008). Our experiment indicated that the best concentration of hormone for embryo yield was the combination of $0.5 \mathrm{mg} / \mathrm{L}$ BAP and NAA on full-strength NLM medium for whole genotypes. The heat shock treatment at $30^{\circ} \mathrm{C}$ for one day gave higher formation of embryo. The efficiency of microspore culture was different among five genotypes, and only three of five genotypes responded positively. It indicated that the different genotypes of red colored Chinese cabbage required different culture conditions. To increase the efficiency of microspore culture of red colored Chinese cabbage, culture medium and condition should be examined extensively.

In this study, plant regeneration frequencies from embryos are often low and variable $(3.1 \sim 16.2 \%)$ depending on genotypes (Table 4). The average plant regeneration frequency was $10.2 \%$, which is higher than those in other studies, while the efficiency of plant regeneration was 5 $10 \%$ in red colored Chinese cabbage (Sato et al. 1989), and
$7.6 \%$ in Pak Choi (Cao et al. 1994). However, not all embryos formed in microspores were able to regenerate into fully developed plants. Embryo quality and the frequency of conversion to plants are still a problem. The concentration of medium has been reported to affect the embryogenesis in microspore culture (Dias 1999; Wakui et al. 1994). Heat shock conditions and media osmolarities have shown to greatly affect abnormal embryo production in microspore culture (Hoekstra et al. 1993). The maintenance of osmolarity at a constant level is important for a high frequency of normal embryo induction and development.

For haploid microspore-derived plants to be useful in a breeding program, chromosome doubling to produce homozygous lines is necessary. In Brassica, the occurrence of spontaneous diploids is primarily governed by genetic factors and influenced by the microspore stage and the culture conditions (Keller and Armstrong 1978; Charne et al. 1988). A high percentage of spontaneous diploids were found in red colored Chinese cabbage (Zhang et al. 2001). Half of 45 genotypes produced $70 \%$ of spontaneous diploid plants. A high percentage of spontaneous diploids were found in broccoli $(55 \% \sim 71 \%)$ and cauliflower $(56 \%)$ (Wang et al. 1999). Such high spontaneous diploidization has not been reported in other Brassica species. In B. rapa ssp. oleifera, the percentage of spontaneous diploids reported is $30 \%$, and $5 \sim 50 \%$ in B. napus (Keller and Armstrong 1975; Charne et al. 1988; Chen and Beversdorf 1992; Mollers et al. 1994; Zhou et al. 2002a, 2002b). In the present study, the spontaneous doubling frequency was near $60 \%$ (Table 4), which is sufficient for exploitation in actual DH breeding programs. Thus an additional step of treatment is not required with chromosome doubling agents.

In this study, the differences between plants of haploid and doubled haploid plants at morphological levels in red colored Chinese cabbage (Fig. 3E-F). In Brassica crops, the difference between plants of different ploidy was also analyzed at the morphological level (Soroka 2013; Zhang et al. 2012). At the same time, pure seeds from doubled haploid plants were successfully obtained (Fig. 4). The pure seed production ability appeared to be similar in both parents. The $\mathrm{H} 1$ generations displayed significant variation for phenotype and were considered fixed (Fig. 4C-E). A 
doubled haploid line is valuable for crop breeding programs because traits are fixed in just one generation, thereby reducing time and cost of cultivar development (Dunwell 2010; Ferrie and Caswe 2010; Germana 2011). Until now, we have obtained 142 doubled haploid plants in four genotypes of red colored Chinese cabbage. The results in the present study are useful for breeding programs in red colored Chinese cabbage.

\section{ACKNOWLEDGMENT}

This work was supported by Bio-industry technology development program (111161-05-3-HD110) of Korea Institute of Planning and Evaluation for Technology in Food (iPET), Republic of Korea.

\section{REFERENCES}

Baillie AMR, Epp DJ, Hutcheson D, Keller WA. 1992. In vitro culture of isolated microspores and regeneration of plants in Brassica campestris. Plant Cell Rep. 11: 234237.

Cao MQ, Li Y, Liu F, Dore' C. 1994. Embryogenesis and plant regeneration of pak choi (Brassica rapa L. ssp. chinensis) via in vitro isolated microspore culture. Plant Cell Rep. 13: 447-450.

Charne DG, Pukacki P, Kott LS, Beversdorf WD. 1988. Embryogenesis following cryopreservation in isolated microspores of rapeseed, Brassica napus L. Plant Cell Rep. 7: 407-409.

Chen JL, Beversdorf WD. 1992. Cryopreservation of isolated microspores of winter rapeseed (Brassica napus L.) for in vitro embryo production. Plant Cell Tiss. Org. Cult. 31: 141-149.

Guo YD, Pulli S. 2000. An efficient androgenic embryogenesis and plant regeneration method through isolated microspore culture in timothy (Phleum pretense L.). Plant Cell Rep. 19: 761-767.

Dias JS. 1999. Effect of activated charcoal on Brassica oleracea microspore culture embryogenesis. Euphytica 108: 65-69.

Dias JS, Correia C. 2002. Effect of medium renovation and incubation temperature regimes on tronchuda cabbage microspore culture embryogenesis. Sci. Hort. 93: 205-214.

Dunwell JM. 2010. Haploids in flowering plants: origins and exploitation. Plant Biotechnol. J. 8: 377-424.

Ferrie AMR, Caswe KL. 2010. Isolated microspore culture techniques and recent progress for haploid and doubled haploid plant production. Plant Cell Tiss. Org. Cult. 104: 301-309.

Gambory OL, Miller RA, Ojima K. 1968. Nutrient requirements of suspension culture of Soybean root callus. Exp. Cell Res. 50: 151-158.

Germana MA. 2011. Anther culture for haploid and doubled haploid production. Plant Cell Tiss. Org. Cult. 66: 59-66.

Gu HH, Hagberg P, Zhou WJ. 2004. Cold pretreatment enhances microspore embryogenesis in oilseed rape (Brassica napus L.). Plant Growth Regul. 42: 137-143.

Guo YD, Pulli S. 1996. High-frequency embryogenesis in Brassica campestris microspore culture. Plant Cell Tiss. Org. Cult. 46: 219-225.

Ho KM, Jones GE. 1980. Mingo barley. Can. J. Plant Sci. 60: 279-280.

Hoekstra S, van Zijderveld MH, Heidekamp F, van der Mark F. 1993. Microspore culture of Hordeum vulgare L.: the influence of density and osmolality. Plant Cell Rep. 12: 661-665.

Keller WA, Armstrong KC. 1975. Stimulation of embryogenesis and haploid production in Brassica campestris anther cultures by elevated temperature treatments. Theor. Appl. Genet. 55: 65-67.

Keller W A, Armstrong KC. 1978. High frequency production of microspore derived plants from Brassica napus anther cultures. Z. Pflanzenzchtg. 80: 100-108.

Leroux B, Carmoy N, Giraudet D, Potin P, Larher F, Bodin M. 2009. Inhibition of ethylene biosynthesis enhances embryogenesis of cultured microspores of Brassica napus. Plant Biotechnol. Rep. 3: 347-353.

Lichter R. 1982. Induction of haploid plants from isolated pollen of Brassica napus. Z. Pflanzenphysiology. 15: 427-434

Maluszynski M, Kasha KJ, Szarejko I. 2003. Published protocols for other crop plants. p. 309-336. In: Maluszynski M, Kasha KJ, Forster BP, Szarejko I. (eds.), Doubled haploid production in crop plants: A manual. Kluwer Academic Publ., Dordrecht, Boston, London.

Murashige T, Skoog F. 1962. A revised medium for rapid growth and bioassays with tobacco cultures. Physiol. 
Plant 15: 473-497.

Möllers C, Iqbal MCM, Robbelen G. 1994. Efficient production of doubled haploid Brassica napus plants by colchicines treatment of microspores. Euphytica 75: 95-104.

Sato T, Nishio T, Hirai M. 1989. Plant regeneration from isolated microspore cultures of Chinese cabbage (Brassica campestris L. ssp. Pekinensis). Plant Cell Rep. 8: 486488.

Wakui K, Takahata Y, Kaizuma N. 1994. Effect of abscisic acid and high osmoticum concentration on the induction of desiccation tolerance in microspore-derived embryos of Chinese cabbage (Brassica campestris L.). Breed Sci. 44: 29-34.

Wang TT, Li HX, Zhang JH, Ouyang B, Lu YG, Ye ZB. 2009. Initiation and development of microspore embryogenesis in recalcitrant purple flowering stalk (Brassica campestris ssp. Chinesis var. purpurea Hort.). Sci. Hortic. 121: 419-424.

Wong RSC, Zee SY, Swanson EB. 1996. Isolated microspore culture of Chinese flowering cabbage (Brassica campestris ssp. parachinensis). Plant Cell Rep. 15: 396-400.

Zhou WJ, Hagberg P, Tang GX. 2002. Increasing embryogenesis and doubling efficiency by immediate colchicines treatment of isolated microspores in Spring Brassica napus. Euphytica 128: 27-37.

Xu L, Najeeb U, Tang GX, Gu HH, Zhang GQ, He Y, Zhou WJ. 2007. Haploid and doubled haploid technology. Adv. Bot. Res. 45: 181-216.

Soroka AI. 2013. Differentiation of haploid and dihaploid Rape plants at the cytological and morphological levels. Cytol. Genet. 41: 88-92.
Stringham GR, Bansel VK, Thiagarajah MR, Degenhardt DF, Tewari JP. 1995. Development of an agronomically superior blackleg resistant canola cultivar Brassica napus L. using doubled haploidy. Can. J. Plant Sci. 75: 437-439.

Thomas WTB, Gertson B, Forster BP. 2003. Doubled haploids in breeding. p. 337-350. In: Maluszynski M, Kasha KJ, Forster BP, Szarejko I. (eds.), Doubled haploid production in crop plants: A manual. Kluwer Academic Publ., Dordrecht, Boston, London.

Wang M, Farnham MW, Nannes JSP. 1999. Ploidy of broccoli regenerated from microspore culture versus anther culture. Plant Breed. 118: 249-252.

Zhang FL, Zhao XY, Zhang DS, Liu F, Xu JB. 2001. High frequency production of doubled haploid plants of Chinese cabbage derived from microspore embryogenesis without colchicines treatment. Cruciferae Newsl. 23: 31-32.

Zhang W, Fu Q, Dai XG, Bao MZ. 2008. The culture of isolated microspores of ornamental kale (Brassica oleracea var. acephala) and the importance of genotype to embryo regeneration. Sci. Hort. 11: 769-772.

Zhou WJ, Hagberg P, Tang GX. 2002a. Increasing embryogenesis and doubling efficiency by immediate colchicine treatment of isolated microspores in spring Brassica napus. Euphytica 128: 27-34.

Zhou WJ, Tang GX, Hagberg P. 2002b. Efficient production of doubled haploid plants by immediate colchicine treatment of isolated microspores in winter Brassica napus. Plant Growth Regul. 37: 185-192.

Zhang Y, Wang A, Liu Y, Wang Y, Feng H. 2012. Improved production of doubled haploids in Brassica rapa through microspore culture. Plant Breed. 131: 164-169. 